Review

\title{
Emphasis Harmony in Arabic: A Critical Assessment of Feature-Geometric and Optimality-Theoretic Approaches
}

\author{
Hussein Al-Bataineh \\ Department of Linguistics, Memorial University of Newfoundland, St. John's, NL A1B 3S7, Canada; \\ hhalbataineh@mun.ca
}

Received: 23 July 2019; Accepted: 17 October 2019; Published: 21 October 2019

\begin{abstract}
This overview article examines vowel-consonant harmony, specifically emphatic harmony (also referred to as pharyngealization, velarization, or uvularization), which is found in Semitic languages. It provides a comprehensive overview of emphasis harmony in Arabic dialects from feature-geometric and optimality-theoretic perspectives. From the feature geometric account, emphatic consonants are considered as a natural class within the guttural group that has the [pharyngeal] or [RTR] 'retracted tongue root' feature. This view has been questioned and challenged recently by some researchers who argue for the exclusion of emphatics from the guttural group. The different arguments discussed in this paper show that researchers cannot reach a consensus regarding which consonants belong to the guttural group and which features are shared between these consonants. This paper shows that studies adopting an optimality-theoretic perspective provide a more comprehensive view of emphasis harmony and its fundamental aspects, namely, directional spreading and blocking, spread from secondary emphatic $/ \mathrm{r} /$ and labialization. However, this paper reaches two main conclusions. Firstly, unlike feature geometry, optimality theory can provide a clearer picture of emphasis harmony in an accurate and detailed way, which does not only clarify the process in one Arabic dialect but also describe the differences between dialects due to the merit of (re)ranking of constraints. Secondly, emphasis harmony is different from one Arabic dialect to another regarding its direction, involvement of emphatic $/ \mathrm{r} /$, and labialization. These differences between dialects indicate that emphasis harmony is not an absolute phenomenon.
\end{abstract}

Keywords: autosegmental phonology; emphasis spread; gutturals; pharyngealization; optimality theory; Semitic languages

\section{Introduction}

Harmony refers to a long-distance assimilatory process in which segments of a particular type agree with each other concerning some phonological feature(s). Depending on the type of segments that cause harmony (triggers) and the segments that assimilate or harmonize (targets), there are three major harmony types: consonant harmony, vowel harmony, and vowel-consonant harmony. These three patterns are well-attested in a wide range of languages (Rose and Walker 2011). This study examines vowel-consonant harmony, specifically emphatic harmony (also referred to as pharyngealization, velarization, or uvularization), which is found in Semitic languages like Arabic, Hebrew, and Aramaic (Laufer and Baer 1988; Sylak-Glassman 2014; see also Shosted et al. 2017). It is triggered by consonants produced with a secondary constriction in the posterior vocal tract and primary constriction typically in the dental/alveolar region, these sounds include emphatic coronal obstruents: /D/, /T/, /Z/, /S/ which contrast with plain counterparts $/ \mathrm{d} /, / \mathrm{t} /, / \mathrm{\delta} /, / \mathrm{s} /$. In Arabic there is a distinction between word pairs

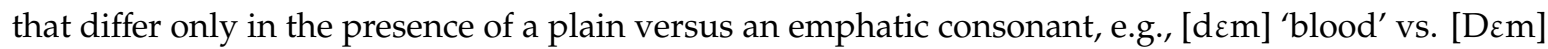


'he hugged' in Jordanian Arabic (Al-Masri and Jongman 2004, p. 100; cited in Rose and Walker 2011, p. 247).

This paper aims to provide a comprehensive view of emphasis harmony. To reach this end, it considers all the possible data from the available studied Arabic dialects (in addition to data from other Semitic languages like Hebrew), and it also considers phonological investigations of emphatic harmony from the two theoretical approaches adopted in the literature, namely, feature geometry and optimality theory. Feature geometric accounts characterize emphatic consonants by hierarchically structured and organized features that function as the terminal nodes in a tree-like hierarchy. Emphatic consonants are considered as a natural class that has the [pharyngeal] (McCarthy 1994) or [RTR] 'retracted tongue

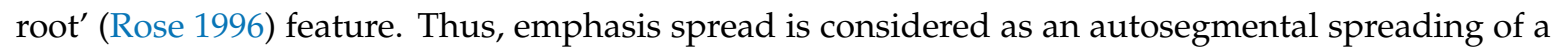
feature from an emphatic consonant to adjacent vowels and consonants. From an optimality-theoretic perspective, emphasis is analyzed as a change from an input to a surface form according to various markedness and faithfulness constraints (e.g., Alghazo 2013; Khedidja and Zhang 2017; McCarthy 1997). These constraints are considered to be responsible for the different properties of emphasis harmony, namely, directional spreading and blocking, labialization, and spreading from secondary emphatic $/ \mathrm{r} /$. Additionally, the variation between Arabic dialects is caused by constraint reranking.

The rest of the paper is organized as follows: Section 2 discusses the phonological arguments for the existence of gutturals as a natural class from a feature-geometric perspective. Section 3 considers the direction of emphasis harmony and related issues from an optimality-theoretic account. Section 4 summarizes and concludes the paper.

\section{Feature-Geometric Analysis}

In this section, the introduction provides a brief discussion about feature geometry and the existence of natural classes. The following two subsections deal with the phonetic and phonological evidence for the [pharyngeal] (McCarthy 1994) and [RTR] (Rose 1996) feature in guttural segments. The last subsection discusses the arguments for the exclusion of emphatics from the guttural class.

\subsection{Natural Classes as Functional Units}

The earliest versions of distinctive feature theory (e.g., Chomsky and Halle 1968; Jakobson et al. 1951) consider all features to have the same status; that is, the focus of these representations was on the features themselves, rather than on their possible groupings, as indicated by Clements (1985, p. 226; cited in Sylak-Glassman 2014, p. 116) that "phonological features are simultaneous and unstructured at the phonological level". However, later studies of the internal composition of speech sounds proposed that phonological features have an internal organization. That is to say, phonological representations include hierarchical groupings of features in terms of phonological tiers. This theory is called 'feature geometry' (FG).

Clements (ibid) indicates that "certain sets of features consistently behave as a unit" in phonological processes, and each of these sets should "constitute a unit in phonological representation". From the perspective of FG, segments are characterized by hierarchically structured and organized features that function as the terminal nodes in a tree-like hierarchy of units of phonological representation. In the feature geometry of Sagey (1990; cited in Sylak-Glassman 2014, p. 116), active articulators (e.g., labial, coronal, etc.) occupy the first-level dominating nodes. These articulator nodes are further linked to a dominating node (e.g., place) in a hierarchical structure as in Figure 1: 


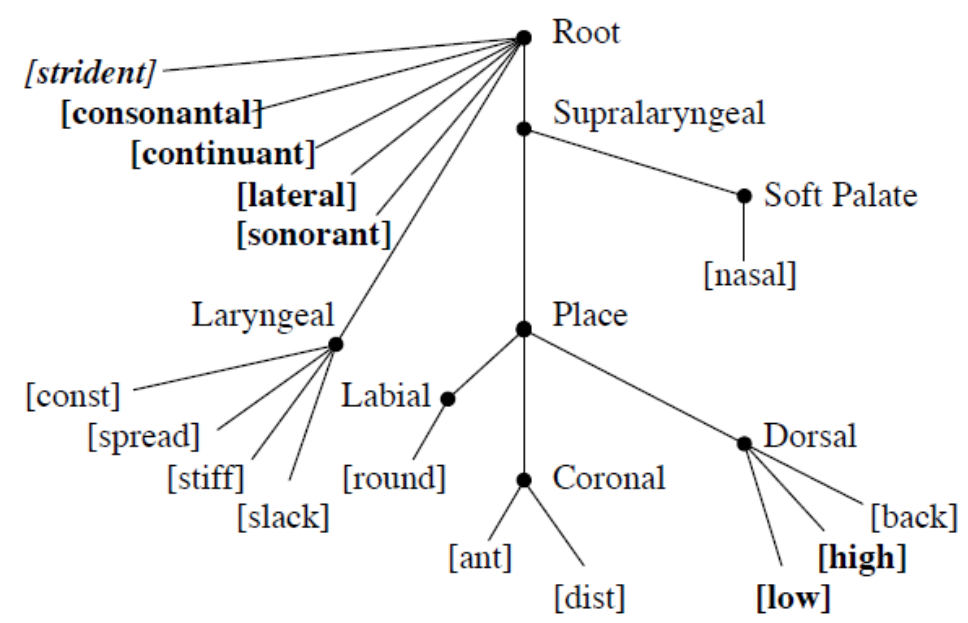

Figure 1. The feature geometry proposed by Sagey (1990, p. 205).

Rose (1996, p. 81) suggests that phonological representations explain the groupings of segments as natural classes in phonological processes and constraints. In a similar vein, Mielke and Hume (2006, p. 726) indicate "the observation that certain features commonly pattern together motivated the idea that there are 'natural groupings' of features that form higher-level functional units". For example, the features [labial], [coronal], and [dorsal] have natural class behavior in many languages; therefore, they function together as a unit under the Place node. In other words, the three place features pattern together as a functional unit in phonological processes like assimilation to the exclusion of features not dominated by the Place node, such as [nasal]. Mielke and Hume (ibid) exemplify this mechanism with the conventional process of homorganic nasal assimilation in Figure 2 below:

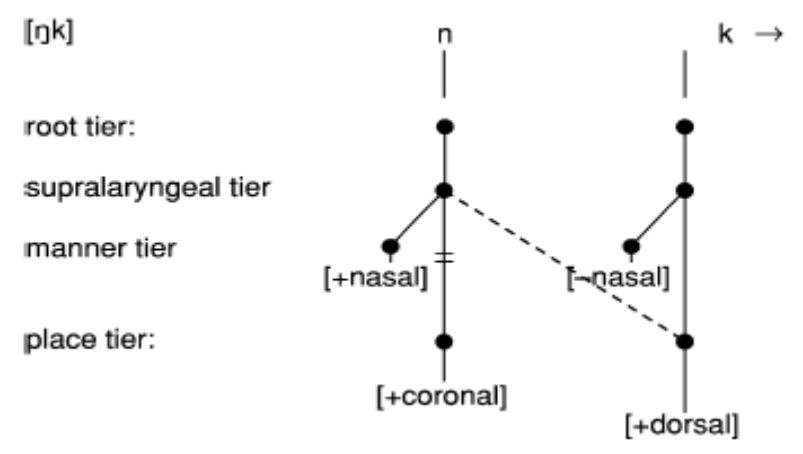

Figure 2. Assimilation in feature geometry (Mielke and Hume 2006, p. 727).

The Place node of $/ \mathrm{k} /$ extends its domain (referred to as 'spreading'), replacing the Place node of the consonant $/ \mathrm{n} /$. As a result, the two sounds share a single Place node that dominates [+dorsal]. Similar to homorganic nasal assimilation, for most authors (e.g., (McCarthy 1994; Watson 2002), and others) emphasis spread in Arabic is considered as autosegmental spreading of a feature from an emphatic consonant to adjacent vowels and consonants. To illustrate, Mahadin and Bader (1995, p. 100) indicate that the first emphatic consonant in tri-consonantal verbs triggers emphasis spread to the following infix/t/, that is, changing/t/ to emphatic [T], as in /SaHiba/- [?iSTaHaba] 'to take company with'. In this example, the change from /St/ to [ST] takes place because of the effect of the emphatic segment /S/ on the following infix $/ \mathrm{t} /$. In the absence of an emphatic segment, no change takes place, that is, $/ \mathrm{t} /$ is spelled out as [t] as in /samiSa/- [?istamaia] 'to hear'. The change of / $t /$ to [T] is represented below (Figure 3): 


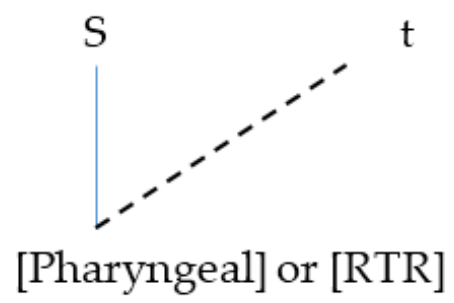

Figure 3. Emphasis spread to the infix $/ \mathrm{t} /$.

The change from / $t /$ to $[\mathrm{T}]$ is caused by the spreading of a feature from the emphatic /S/. The feature can be either [Pharyngeal] (McCarthy 1994) or [RTR] 'retracted tongue root' (Rose 1996)' What is essential from an FG account is to specify which feature exists in emphatic segments that spreads to other segments since the process itself is straightforward and agreed upon by researchers. In Halle et al. (2000, pp. 425-26)'s view, a hypothetical word tatataT would surface as [TaTaTaT] since the last coronal emphatic spreads emphasis onto the preceding consonants.

\subsection{Guttural Segments and the [Pharyngeal] Feature}

McCarthy (1994) provides phonetic and phonological evidence from Semitic languages for the existence of a natural class called 'guttural' which comprises all post-velar consonants (i.e., emphatics, pharyngeals, uvulars, and laryngeals). McCarthy (1994, p. 196) offers a detailed examination of the acoustic and articulatory properties of the Semitic gutturals and finds that they share the following phonetic properties:

1- Active articulator. The gutturals are produced by three distinct gestures: a purely glottal one in the laryngeals, retraction of the tongue root and epiglottis and advancement of the posterior wall of the laryngopharynx in the pharyngeal, and a superior-posterior movement of the tongue dorsum in the uvulars.

2- Place of articulation. The gutturals are all produced in the posterior region of the vocal tract.

3- Spectrum. The gutturals all have relatively high $\mathrm{F}^{2}$. $\mathrm{F} 1$ is at the theoretical maximum in the case of laryngeals, close to the maximum for the pharyngeal, and higher than any orally articulated consonants in the case of uvulars.

4- Stricture. All gutturals except [?] meet Catford's (1977, p. 122) definition of approximant: "non-turbulent flow when voiced; but the flow becomes turbulent when they are voiceless". Clements (1990) revises this definition to require oral stricture in non-approximants. With this modification, even [?] is included in the class of approximants.

These four features indicate that gutturals share a posterior place of articulation, high F1, and stricture, but they do not share an active articulator. Although gutturals do not share the same articulator, they share the [pharyngeal] place, that is, the same region of the vocal tract that "encompass[es] the area from the larynx and oropharynx inclusive", and the proposed feature [pharyngeal] is defined as "the orosensory pattern of constriction anywhere in the broad region of the pharynx" (McCarthy 1994, pp. 198-99).

Additionally, McCarthy provides several phonological arguments for the gutturals as a natural class. The phonological evidence covers co-occurrence restrictions, vowel lowering, avoidance of

1 The [pharyngeal] feature distinguishes sounds articulated in "the area from the larynx and oropharynx inclusive" (McCarthy 1994, p. 198). (Rose 1996) argues that the pharyngeal sounds are divided into two subgroups according to the shape of the tongue root: the first subgroup include non-laryngeals sounds (i.e., uvulars, pharyngeals and emphatics) that have the [RTR] feature because they are articulated by constricting the pharynx or retracting the tongue root, and the second subgroup includes only laryngeals that have [ATR] feature since they are produced with tongue root advancement, rather than retraction (for an overview, see (Vaux 1996)).

2 Compared with F2 which ranges from 1200-1400 Hz, F1 is relatively high as it ranges from 900-1000 (McCarthy 1994, p. 196). 
syllable-final position, and degemination. Regarding the co-occurrence restrictions, McCarthy indicates that certain combinations of consonants in the same root are avoided in Semitic languages. According to Greenberg (1950, p. 162), identical or homorganic first and second consonants in triconsonantal verb morphemes are prohibited (e.g., labials like ${ }^{*} b m$ - or velars like ${ }^{*} g k$ - are excluded in the first two positions). The same restrictions apply on gutturals, that is, combinations of two gutturals rarely occur in Arabic except in some verbs like [xT?] 'to err, sin'; [?xð] 'to take, seize' (Greenberg 1950, p. 171) (although the co-occurrence of emphatics with pharyngeals is widespread, according to Altairi et al. (2017), as explained below). The observation that roots combining two gutturals are significantly infrequent supports the view that gutturals form a natural class in compliance with the Obligatory Contour Principle (McCarthy 1994, p. 206), which prohibits identical elements from being adjacent.

Concerning vowel lowering in a guttural context, McCarthy provides evidence from both Arabic and Hebrew. Arabic verbs, including a guttural sound, have the [pharyngeal] feature spread from the guttural to the adjacent thematic vowel, changing it to [a]. In Hebrew, the epenthetic vowel in singular nouns is lowered by a preceding guttural as in (1b) (McCarthy 1994, p. 210):

(1) a. Plain roots: /malk/ [melek] 'king/my king', /sipr/ [se:per] 'book'

b. Medial guttural roots: /baSl/ [baial] 'master', /lahb/ [lahab] 'flame'

In contrast with (1a), the epenthetic vowel in (1b) becomes lowered when preceded by a guttural by a process formulated as follows (Figure 4):

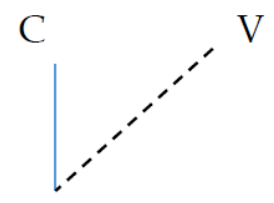

[Pharyngeal]

Figure 4. Hebrew guttural lowering (McCarthy 1994, p. 210).

Concerning the avoidance of syllable-final position, McCarthy (1994, p. 214) points out that guttural codas are prohibited in Semitic languages, the guttural shifts out of the coda position to become the onset of a new syllable by epenthesis like in Negev Bedouin Arabic below:

(2) a. Plain roots: [ja $\left.\int \mathrm{rab}\right]$ 'he drinks', [a $\left.\mathrm{arab}\right]$ 'I drink'

b. Guttural roots: [jahard 3 ] 'he speaks', [aHalam] 'I dream' ${ }^{3}$

While plain consonants can be in the coda position as in [jaf.rab], gutturals cannot, and epenthesis of the vowel [a] is required to make the guttural occupy the onset position as in [ja.hard3]. The same phenomenon occurs in Hebrew, as can be seen in a plain root like [jik.to:b] 'he will write' and a guttural root like [ja.\{â.mo:d] 'he will stand' (McCarthy 1994, p. 215).

In addition, Hebrew and Tigre have a constraint against guttural gemination, as can be seen in the contrast between (3a) and (3b) from Hebrew.

(3) a. Plain roots: [dibbe:r] 'he said', [dalli:m] 'weak ones'

b. Guttural roots: [me:?e:n] 'he refused', [ra:Si:m] 'evil ones'

In contrast with plain consonants, gutturals are degeminated by compensatory lengthening, that is, the preceding vowel gets lengthened instead of geminating the guttural.

3 Based on the reviewer's fieldwork, the forms [jahard3] 'he speaks' and [aHalam] 'I dream' have different pronunciations than the given ones. [jahard 3 ] is produced as [jaharrid 3 ] or [jaharid 3 ] with epenthesis, as indicated by McCarthy, but [aHalam] is articulated without the second [a] vowel as [aHlam], which may render the guttural in coda position since the epenthesis of [a] does not take place. Assuming the correctness of the reviewer's observation, the avoidance of a guttural in coda position may not be a strong piece of evidence due to the existence of some exceptions. 
All the previous phonetic and phonological pieces of evidence support the existence of the guttural natural class, which includes not only proper gutturals but also pharyngealized sounds-the coronal emphatics [S], [D], [T], and [Z], and the uvular stop [q] ${ }^{4}$ - because "the emphatics and [q] have a constriction in the upper pharynx similar to that of the uvular gutturals"; therefore, the Arabic pharyngealized consonants should be called uvularized (McCarthy 1994, pp. 218-19). The phonetic resemblance between gutturals and emphatics and [q] corresponds to two types of phonological patterning. The first type includes a class of primary and secondary [pharyngeal] sounds (i.e., gutturals, emphatics, and [q]). An example of this phonological patterning comes from Herzallah's (1990; cited in McCarthy 1994, p. 219) analysis of imaala (raising/fronting) of the feminine suffix. In many Eastern Arabic dialects like Syrian Arabic, the feminine suffix /a/ appears as [e] or [i] except when a [pharyngeal] sound precedes it. Consider (4a,b):

(4) a. [daradze] 'step', [kbi:re] 'large', [madrase] 'school'

b. [?əSSa] 'story', [ [ar:Da] 'broad', [xayya:Ta] 'seamstress'

In (4a), the feminine suffix /e/ does not change since it is preceded by a non-guttural consonant whereas it gets raised and fronted when preceded by an emphatic sound. The connection between gutturals and emphatics also appears in historical changes in which an emphatic sound becomes a guttural. According to McCarthy (1994, p. 220), examples of this include [Z] in Ugaritic which becomes $[\mathrm{r}]$, and [D] in Aramaic which changes to [C].

The second type of phonological patterning includes a class of sounds with [pharyngeal] constriction produced by the [dorsal] articulator (i.e., uvular gutturals, emphatics, and [q]). An example of this type comes from the phenomenon of backing or emphasis spread in Arabic. The class of

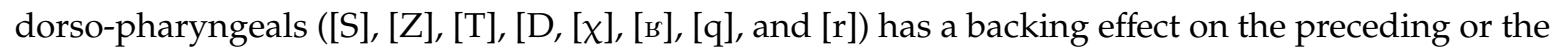
following vowel. Based on the preceding arguments, McCarthy (1994, p. 221) represents the guttural sounds as follows (Figure 5):

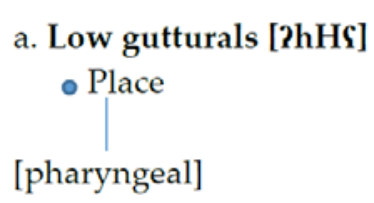

c. Coronal emphatics [TDSZ]

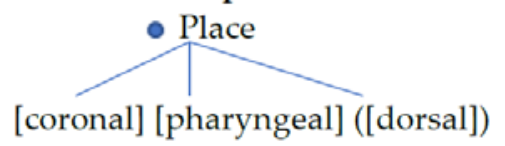

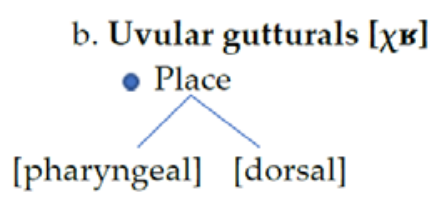

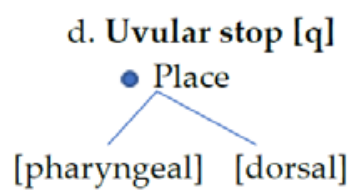

Figure 5. Representation of gutturals McCarthy (1994, p. 221).

McCarthy concludes that the gutturals constitute a natural class, and they share the same [pharyngeal] place of articulation that covers the region from oropharynx to larynx inclusive. The difference between primary and secondary gutturals is that the proper gutturals are approximants, while emphatics and [q] are not.

\subsection{Guttural Segments and the [RTR] Feature}

Rose (1996) agrees with McCarthy (1994) that guttural consonants have several phonological properties that make them a natural class, but she argues that laryngeals are different from other gutturals because they are specified with a pharyngeal node in some languages and they are placeless in others. The reason behind the special status of laryngeals is that they "are specified as pharyngeal only

4 It is not clear whether emphatics undergo the same processes like other gutturals. The only pieces of evidence for the inclusion of emphatics in the guttural class are imaala (raising/fronting) and emphasis spread (backing). 
when pharyngeals or uvular continuants are also present in the inventory of the language; otherwise, they are placeless" (Rose 1996, p. 73). This argument is based on Avery and Rice's (1989; cited in Rose 1996, p. 78) Node Activation Condition, which states: If a secondary content node is the sole distinguishing feature between two segments, then the primary feature is activated for the segments distinguished. Active nodes must be present in the underlying representation. Under the given assumptions, Rose (1996, p. 80) proposes a representation of gutturals similar to McCarthy's model except for the replacement of the [pharyngeal] feature with the [RTR] 'retracted tongue root' feature to distinguish between laryngeals and non-laryngeals. The [RTR] feature is used to characterize all non-laryngeal gutturals since uvulars, pharyngeals, and emphatics are produced by retracting the tongue root or constricting the pharynx. The following representation is illustrative (Figure 6):
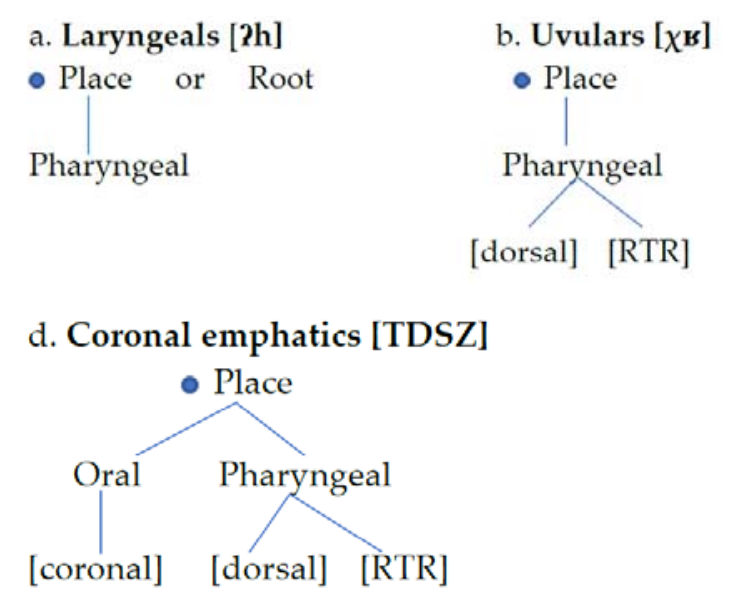

Figure 6. Representation of gutturals (Rose 1996, p. 80).
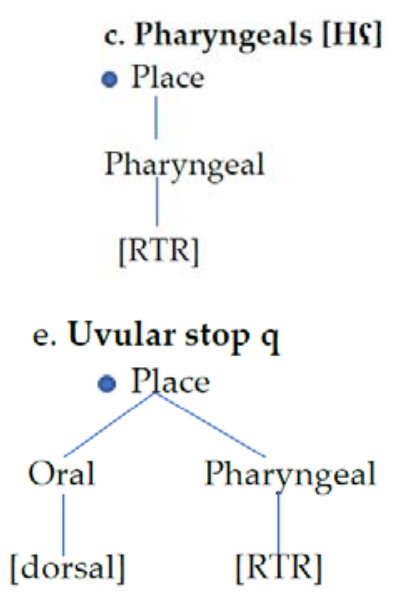

In support of these representations, Rose provides numerous pieces of evidence which include vowel retraction/ lowering, translaryngeal harmony, debuccalization, coda constraints, and epenthesis from a number of languages like Ethio-Semitic languages (e.g., Tigrinya and Tigre), the Caucasian languages (e.g., Besleney), the Chadic language (e.g., Kera), and others. Due to space, only the first phenomenon is discussed in detail. Vowel retraction/lowering is evidenced in several languages like Salish and Afroasiatic, which show that uvulars, pharyngeals, and emphatics retract a preceding vowel, as illustrated in (5a-c) (Rose 1996, p. 83). Laryngeals do not cause vowel retraction (5d), that is, the preceding vowel does not change, and no retraction takes place.

(5) a. $/$ ?iq't/ [?eq't] 'scraped off'

b. $/ \mathrm{i} \mathbf{u} \mathrm{q}^{\mathrm{w}} \mathrm{e}$ ?/ $\quad\left[\mathrm{loq}^{\mathrm{w}} \mathrm{e}\right.$ ? $]$ 'drink'

c. $/ \mathrm{m} ə \mathrm{~S}^{\prime} \mathrm{t} / \quad\left[\mathrm{m} \Lambda \mathrm{S}^{\prime} \mathrm{t}\right]$ 'broken'

d. /ni?helus/ [ni?helus] 'good-natured'

The reason behind this phenomenon is that laryngeals cannot have the [RTR] feature because their production does not involve the tongue root. Other evidence comes from Arabic emphasis that spreads from coronal emphatics to some vowels within a particular domain. The emphatic sounds retract (i.e., lower and back) vowels. For example, in Moroccan Arabic, emphatics retract the underlying vowels /a/, /i/, and /u/ to [a], [e], and [o] (Rose 1996, p. 85):

(6) /Dar/ [Dar] 'he returned', /Sif/ [Sef] 'summer', /Zur/ [Zor] 'visit'

Based on the previous arguments of Arabic and other languages, Rose (1996, p. 87) argues that emphasis harmony found in Arabic and Berber involves the feature [RTR] because this feature groups all emphatics, uvulars, and pharyngeals, to the exclusion of laryngeals.

However, one of the Totonac-Tepehua languages in eastern Mexico, namely, Filomeno Mata Totonac, represents a direct counterexample to Rose's (1996) framework. According to 
McFarland (2009, pp. 35-37; cited in Sylak-Glassman 2014, pp. 123-24), the post-velar consonant phoneme inventory of this language has only /q/ and / $/ /$, and these consonants pattern together in causing vowel lowering. Vowel lowering indicates that both / $q /$ and / $/$ / bear Pharyngeal nodes, and that is assumed to be impossible under Rose's (1996) analysis. Further counterarguments are in the following subsection.

\subsection{Counterarguments and the Exclusion of Emphatics}

Al-Solami (2013) provides phonological and phonetic evidence against McCarthy's (1994) and McCarthy's (1994) proposals. He argues that Arabic emphatics should be excluded from the Arabic guttural class. Phonological evidence includes several processes (mainly from the phonology of the Holy Quran, referred to as Tajweed) that the previous proposals cannot account for. The first process is called Tiðhar 'pronunciation of $/ \mathrm{n} /$ ' which is triggered only by laryngeals, pharyngeals, and uvulars, exemplified in (7) to the exclusion of emphatics and /q/ which trigger the opposite process, exemplified in (8).

(7) [?aniamta] 'those whom Thou hast favored', [yan?awana] 'avoid' ${ }^{5}$, [yanHitun] 'they used to hew out dwellings from the hills' (Al-Solami 2013, p. 315)

(8) [min Tin] 'an essence of clay', [manDud] 'clustered', [min qaraar] 'possessing no stability'

In (7), laryngeals, pharyngeals, and uvulars behave as a natural class which prevents the assimilation of a preceding $/ \mathrm{n} /$ (a process is found not only in classical Arabic but also in some varieties like Sudanese Arabic). In (8), emphatic sounds and uvular/q/ trigger the opposite process called iixfaa 'non-pronunciation of $/ \mathrm{n} /$ ' in which the preceding nasal $/ \mathrm{n} /$ cause emphatics and [q] to be articulated through the nasal cavity. However, this argument may not be strong evidence since it is not physically possible to have a pharyngeal or laryngeal nasal, and this phenomenon exists only in the phonology of the Holy Quran, but not in colloquial Arabic varieties.

Moreover, Al-Solami mentions a number of counterexamples of McCarthy's (1994) constraint against the co-occurrence of two guttural sounds in Arabic roots. Al-Solami shows that the co-occurrence can take place between a guttural sound and an emphatic one in roots like [TmS] 'greed', a guttural sound, and the uvular/q/ as in [qmi] 'suppression', and an emphatic, and the uvular/q/as in [qTi] 'cut'. Furthermore, the avoidance of gutturals in syllable final position in Arabic dialects (McCarthy 1994) is true for all gutturals except emphatic sounds and uvular /q/. In Bedouin Hijazi Arabic, / / / and $/ \mathrm{h} /$, pharyngeals $/ \mathrm{S} /$ and $/ \mathrm{H} /$, and uvulars $/ \mathrm{s} /$ and $/ \mathrm{x} /$ are not allowed in coda position (e.g., /mas.rib/ [тьа.rib] 'sunset', /rax.mah/ [rхa.mah] 'coward') while emphatic sounds and uvular/q/are permitted in this position (e.g., [?iT.lâ] 'come out', [?aD.rub] 'I hit', [maS.lax] 'slaughter house').

In a similar vein, Altairi et al. (2017) indicate that empirical data contradicts McCarthy's (1994) and McCarthy's (1994) proposals that emphatics are pharyngealized. They highlight that pharyngeals are free to co-occur with emphatic consonants, suggesting that their phonetic properties are different. Another difference is that nasal $/ \mathrm{n} /$ and lateral $/ 1 /{ }^{6}$ are assimilated to the emphatics, but not to the pharyngeals. Moreover, the pharyngeals, but not the emphatics lower neighboring vowels (Altairi et al. 2017, p. 1).

Concerning the co-occurrence of emphatics with pharyngeals, Altairi et al. (ibid) provide examples such as [SaSb] 'difficult', [HaTab] 'firewood', [iaSab] 'nerve'. Another process involves the articulation of $/ \mathrm{n} /$ before laryngeals, pharyngeals, and uvulars, as in (9):

(9) [man ?a:mana] 'who believed', [min ha:d] 'any guide', [Sali:mun Haki:m] 'hearing and knowing'

5 The correct pronunciation of 'avoid' is [yan?awna], rather than [yan?awana], as correctly pointed out by the reviewer.

6 As pointed out by the reviewer, the assimilation of lateral / $1 /$ cannot be considered a strong piece of evidence since it occurs because emphatics are part of the "sun sounds" groups in Arabic but the assimilation of lateral /1/ does not occur with gutturals as they are part of the "moon sounds". The assimilation of the lateral /1/ also occurs with other non-emphatic consonants as well such as $/ \mathrm{n}, \mathrm{d}, \theta, \mathrm{\partial} /$. 
In contrast, emphatics or the uvular /q/ trigger the deletion of $/ \mathrm{n} /$, as in (10):

(10) /min qabl/ [mĩ qabl] 'before', /man Su:ra/ [mã Su:ra] 'supported', /kalimatan Tayyibah/ [kalimatãTayyibah] 'good word' (Altairi et al. 2017, p. 2)

The assimilation of the lateral/1/ to emphatic coronals, but not to the gutturals, is exemplified in (11):

(11) /Ral Sabr/ [?aS Sabr] 'the patience', / Ral Tifl/ [?aT Tifl] 'the child', /Pal Haq/ [?al Haq] 'the truth'.

The final process is related to lowering the vowel when preceded by a guttural, but not by an emphatic, as can be seen in the contrast between [Darab] [jaDrib] 'hit' and [ðahab] [jaðhab] ' $\mathrm{go}^{\prime 7}$. Altairi et al. (2017) conclude that McCarthy's (1994) proposal of the inclusion of emphatics within the guttural group does not account for the previous processes mentioned above. Moreover, Rose's (1996) argument for the feature [RTR] to be assigned to emphatics, uvulars, and pharyngeals does not distinguish between these sounds and does not provide a satisfactory explanation for the co-occurrence restrictions and other phonological phenomena.

Additionally, Al-Solami provides phonetic evidence for the exclusion of emphatics and uvular /q/ from the guttural group. Concerning articulation, the articulation of pharyngeals requires only the retraction of tongue root; other parts of the tongue are not involved. Uvulars and emphatics, on the other hand, are produced by movement of the entire tongue, not only tongue root movement is involved. The acoustic consequence of the differences in articulation can be supported by the observation that emphatics and uvulars "have low F2 in adjacent vowels as their main acoustic cue rather than high F1" (Al-Solami 2013, p. 315). In a recent study, Al-Solami (2017) supports this remark by citing other studies (e.g., Al-Ani 1970; Bin-Muqbil 2006; Ghazeli 1977) which indicate that the coarticulatory effect of emphatics on adjacent vowels is a lower F2 value. Similar views are held by Moisik et al. (2012, p. 4), who indicate that "the tongue root model and the pharyngeal constriction model—cannot be said to be phonetically adequate". Assuming the correctness of the previous arguments, we can postulate that neither the [pharyngeal] nor [RTR] features can be the shared component for all Arabic gutturals. Thus, agreeing with the given counterarguments, this study claims that emphatics and uvular [q] may not be considered as part of the guttural group. Proposals assuming the inclusion of emphatics and uvular [q] within the guttural group may be questionable and inadequate to account for some phonetic facts and phonological processes found in Arabic.

\subsection{Strengths and Weaknesses of Feature Geometry}

The given arguments in the studies above lead to a number of observations regarding the adequacy of the FG approach. These observations can be summarized and presented as points of strengths and weaknesses of this approach. The main strength that can be clearly seen is that all researchers agree that the process of emphasis harmony is an autosegmental spreading of a phonological feature from a consonant belonging to the guttural group to adjacent vowels and consonants. The second point is that recent studies adopting optimality theory still utilize the notion of feature spreading as used in feature geometry to propose some markedness constraints to account for emphasis harmony, as well as other phonological processes such as labialization (e.g., see Youssef 2015). Apart from these points, the FG approach suffers a number of weaknesses that can be argued as follows: Firstly, researchers cannot reach a consensus regarding which consonants belong to the guttural group and which features are shared between these consonants. While McCarthy argues that all post-velar consonants are included in the guttural class by sharing the [pharyngeal] feature, Rose states that this feature does not exist in all gutturals and the feature [RTR] is needed to differentiate between laryngeals and non-laryngeals.

7 Lowering of the vowel does not take place in all verbs, as highlighted by the reviewer, verbs like [saial] [jasiul] 'cough' [daxal] [jadxul] 'enter' do not involve lowering of the vowel. 
In recent studies provided above, the grouping of non-laryngeals as one natural class is questioned and rejected since emphatics and the uvular [q] have different phonological behavior than other gutturals. The conclusion of these proposals is that FG may be inadequate to provide an accurate description of gutturals simply because one phonological feature cannot be shared between all gutturals in all languages (and most probably, not even all varieties of the same language (e.g., Arabic)).

Secondly, there is wide disagreement among researchers regarding the consonants that trigger emphasis harmony in Arabic, in some studies (e.g., McCarthy 1994), dorso-pharyngeal sounds (i.e., [S], $[Z],[T],[D],[\chi],[\mathrm{s}],[\mathrm{q}]$, and [r]) trigger emphasis harmony and lead to a backing effect on the adjacent segments. In other studies (e.g., Rose 1996), emphatics, uvulars, and pharyngeals cause emphasis harmony. In these different views, the class of low gutturals (i.e., [?], [h], [H], [i]) is excluded in the first and included in the second, and the opposite pattern exists concerning the $[\mathrm{r}]$ sound which is regarded as a trigger of harmony by one view but not the other. The third weak point is related to the direction of spreading and blocking effects. From an FG perspective, emphasis harmony is considered as an autosegmental process that affects adjacent vowels and consonants with no indication of which direction the spread takes place and which segments block harmony and why. This demerit is caused by the essence of FG that focuses on the grouping of sounds by virtue of the presence/ absence of a particular feature, that is, FG may attempt to account for blocking segments in terms of their feature specifications, but it is unable to demonstrate clearly how that can be explanatory for segments that block harmony in one direction but not the other. The fourth point is related to differences in the application of emphasis harmony. FG wrongly predicts that the process of spreading is an absolute phenomenon in the sense that it has the same effect in all varieties of Arabic language. This prediction is proven to be contrary to facts, as studies adopting optimality theory approach indicate.

\section{Optimality Theory}

This section considers a number of studies that adopt optimality theory (OT) as the analytical framework to analyze emphasis harmony which is considered as the result of the interaction of markedness and faithfulness constraints. Three types of constraints are crucial for the analysis of emphasis harmony, namely, correspondence constraints, alignment constraints, and grounded constraints. Correspondence constraints are related to the faithfulness between input and output forms. According to McCarthy and Prince (1995, p. 262), "given two strings S1 'string 1' and S2 'string $2^{\prime}$, correspondence is a relation R from the elements of S1 to those of S2", that is, the elements of both strings are correspondents of one another. In order to guarantee the featural identity of correspondent elements in S1 and S2, the MAX (i.e., Every segment of S1 has a correspondent in S2.), DEP (i.e., Every segment of S2 has a correspondent in S1), and IDENT (i.e., Correspondent segments are identical in feature F) constraint families come into play. These correspondence constraints, especially DEP and IDENT, are essential for the analysis of emphasis harmony since some epenthetic segments are prohibited in the derivation of emphasis, and the [RTR] feature must be present in the output, that is, the emphatic sound must not be de-emphasized.

The second relevant constraint type consists of alignment constraints, which require that a designated edge of a prosodic or morphological constituent of type Cat1 'category 1 ' coincides with a designated edge of some other prosodic or morphological constituent Cat2. These well-formedness alignment constraints are the basic driving force behind emphasis harmony which can be rightward or leftward due to the RTR-RIGHT and RTR-LEFT constraints, respectively.

The last set includes grounded constraints which demand, according to Archangeli and Pulleyblank (1994, p. 172; cited in Shahin 2003, p. 45), that featural relations are "rooted in the physical properties of the vocal tract or speech signal", that is, phonetic bases of speech affect featural constraints. To illustrate, Shahin $(2003$, p. 45) indicates that "a segment specified for [HI] 'high' cannot also be specified for [RTR] [since] this is grounded in the anatomical proximity of the tongue body and root. Given the proximity, raising the body makes it difficult to simultaneously retract the root". Emphasis harmony (in northern Palestinian Arabic, for example) involves the high ranking constraint 
$\mathrm{RTR} / \mathrm{Hi}$, which prohibits the spread of the [RTR] feature to high segments. In the discussion below, the interaction between the three sets of constraints, namely, correspondence constraints, alignment constraints, and grounded constraints, provides the optimal outputs in emphasis harmony.

The OT analysis of emphasis is divided into three subsections. The first subsection explains how the rightward direction of emphasis harmony is different from the leftward direction in being subject to blocking effects of high front segments. The second subsection deals with the enhancing feature of labialization which accompanies pharyngealization in the emphasis process. The third considers the effect of the secondary emphatic [r].

\subsection{Directional Spreading and Blocking}

Emphasis harmony can operate in a leftward (regressive) or rightward (progressive) direction, or bidirectionally. This section discusses how directional spreading and blocking are expressed by faithfulness and markedness constraints in order to decide which direction is the unmarked or default pattern in Arabic dialects.

\subsubsection{Leftward Harmony}

Leftward emphasis spread affects all the segments in a form across Arabic dialects. In Palestinian dialects, for example, documented by Davis (1995) and analyzed by McCarthy (1997, p. 232), show leftward harmony to be unimpeded by any segment. Both dialects show leftward harmony of [RTR] to be unrestricted within the word, as can be seen in (12):

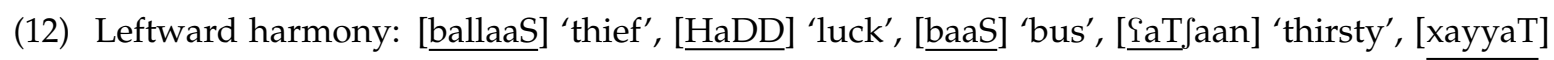
'tailor's

In this list, the emphatic segments [S], [D], and [T] trigger harmony to the preceding segments; that is, both vowels and consonants have the [RTR] feature from the pharyngealized coronal. This process is not blocked by any segment (e.g., [xayyaT]), unlike rightward harmony (see the next section below). To account for this pattern, McCarthy (1997) proposes a number of faithfulness and markedness constraints. The faithfulness constraint IDENT-ATR requires that an input segment that has the feature [ATR] 'advanced tongue root' must retain this feature in the output. IDENT-ATR is dominated by the markedness constraint RTR-LEFT which requires harmony of the feature [RTR] (McCarthy 1997, p. 235):

(13) RTR-LEFT Align([RTR], Left, Word, Left) "Any instance of [RTR] is aligned initially in Word" ${ }^{9}$

RTR-LEFT assigns a violation mark to every segment between the leftmost RTR segment and the left edge of the word. The ranking of these constraints is RTR-LEFT >> IDENT-ATR, as shown in the following tableau:

(14) Leftward harmony (McCarthy 1997, p. 235)

$\begin{array}{lll}\text { /ballaaS/ } & \text { RTR-LEFT } & \text { IDENT-ATR } \\ \text { a. } & \text { ballaaS } & \\ \text { b. ballaas } & * \text { ******* } & \end{array}$

8 Throughout the paper, the effects of emphasis harmony are assumed not to be allophonic in nature, rather, as a result of neutralising effects. The process of emphasis creates contrastive pairs which cannot be in complementary distribution,

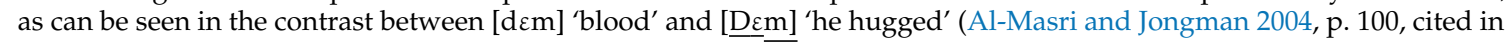
Rose and Walker 2011, p. 247).

9 Although it is not argued in the paper whether the winner has a single RTR feature that is multiply-linked (as in feature geometric approaches) or multiple [RTR] features. I assume that the alignment constraints cause [RTR] feature to be multiply-linked (more details are in Section 3.3 below). 
Candidate (a) satisfies the requirement of RTR-LEFT since the emphatic segment/S/ in /ballaaS/ spreads the feature [RTR] to all the preceding segments but incurs four violations of IDENT-ATR for not retaining the underlying ATR feature in the output (long segments or geminates are considered as single sounds). Candidate (b) loses the competition because it violates the high-ranking constraint RTR-LEFT by not spreading the [RTR] feature to preceding segments. The actual output is candidate (a) in which the emphatic/S/ triggers leftward harmony to all segments. The same phenomenon occurs in northern Jordanian Arabic (Alghazo 2013), Syrian (Habib 2012), San'ani and Cairene (Watson 2002), Qatari (Mustafawi 2006), and Libyan Arabic (Algryani 2014).

\subsubsection{Rightward Harmony}

Progressive spread of the [RTR] feature is also triggered by pharyngealized segments. Unlike leftward harmony, rightward harmony is more vulnerable to high front segments which act as blockers to the process. Returning to Palestinian dialects, according to McCarthy (1997, p. 233), rightward harmony in the Southern variety is blocked by any of the high front sounds [i], [y], [j], and [j], as in (15b):

(15) (a) Rightward harmony: [SabaaH] 'morning', [?aTfaal] 'children', [Tuubak] 'your blocks', [Twaal] 'long.pl', [Sootak] 'your voice', [Seefak] 'your sword'

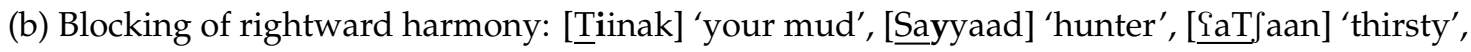
[Dajjaat] 'type of voice.pl'

(15b) shows that rightward harmony is impeded in the first form [Tiinak] by [i], and the other words show how [y], [j], and [j] put a stop to harmony. (15a) demonstrates that in the absence of any blocker, rightward harmony affects all the following segments. McCarthy (1997, p. 235) suggests that RTR-RIGHT dominates IDENT-ATR as in (16):

(16) Rightward harmony (McCarthy 1997, p. 235)

$\begin{array}{lll}\text { /SabaaH/ } & \text { RTR-RIGHT } & \text { IDENT-ATR } \\ \begin{array}{l}\text { a. 唵 SabaaH } \\ \text { b. SabaaH }\end{array} & * \text { ******* } & \end{array}$

This tableau demonstrates that rightward harmony spreads from the emphatic/S/ to all the following segments since there are no blockers (i.e., [i], [y], [j], and [j]).

McCarthy (1997, p. 236) explains the blocking effects of the high front segments as resulting from a conflict between the [RTR] alignment constraint and the featural constraint RTR/HI\&FR (*[high, front, RTR]). This constraint prohibits the specification of RTR on high front vowels. According to Watson (2002, p. 276), high front segments are articulated with pharyngeal expansion, which is incompatible with the pharyngeal constriction of the emphatic coronals. RTR/HI\&FR 'retracted tongue root/ high and front' is highly ranked. It dominates RTR-RIGHT in order to account for the blocking effects of high front segments, as in (17):

(17) Rightward harmony and featural constraint RTR/HI\&FR (McCarthy 1997, p. 236)

\begin{tabular}{lll}
$\begin{array}{l}\text { /Sayyaad/ } \\
\text { a. 实 Sayyaad }\end{array}$ & RTR/HI\&FR & $\begin{array}{l}\text { RTR-RIGHT } \\
\text { S** } \\
\text { b. Sayyaad }\end{array}$ \\
\hline
\end{tabular}

Although candidate (a) incurs three violations of RTR-RIGHT for not spreading the [RTR] feature to the following sounds $/ \mathrm{y} /, / \mathrm{a} /$, and $/ \mathrm{d} /$, it wins the competition because it does not violate the high-ranking constraint RTR/HI\&FR. Rightward harmony is blocked by the high and front segment $/ \mathrm{y} /$, and it does not proceed further to all segments in the word. Candidate (b) loses the competition because it incurs a fatal violation of RTR/HI\&FR. In other words, the high front segments cannot 
become [RTR] themselves without violating RTR/HI\&FR, nor can they be skipped over because they will violate high-ranking NO-GAP, a constraint requiring a phonological feature to be linked to adjacent segments (Archangeli and Pulleyblank 1998, cited in McCarthy 1997, p. 236) (although the NO-GAP constraint is not included in the ranking of the given dialects, the study assumes that it occupies an initial position preceding other constraints by virtue of its being highly ranked and its requirement must be met regardless of the direction of the spreading). McCarthy (1997, p. 236) suggests the full ranking for southern Palestinian Arabic as follows:

\section{(18) RTR-LEFT >> RTR/HI\&FR >> RTR-RIGHT >> IDENT-ATR}

This ranking demonstrates that leftward harmony is unaffected by any segments (not even by high and front ones), and it proceeds regardless of the preceding sounds. Rightward harmony is affected by following high and front segments which cannot be [RTR] themselves ${ }^{10}$.

The directional blocking appears more complicated and requires more markedness constraints in the northern Palestinian Dialect. Two processes of rightward harmony, namely, local and long-distance, appear in this dialect as follows (McCarthy 1997, pp. 241-42):

(19) a. Local rightward harmony

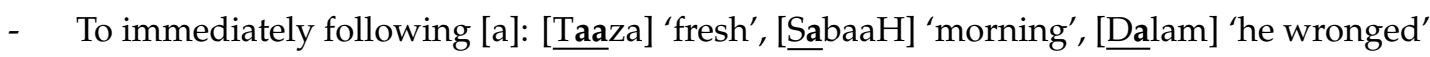

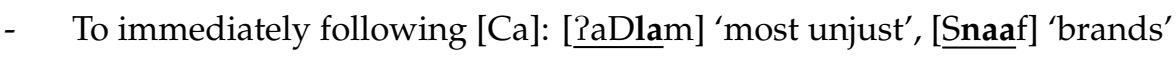

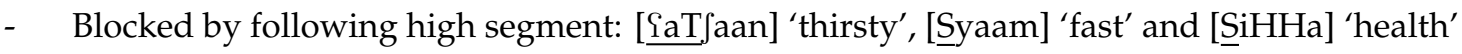

b. Long-distance rightward harmony

- To following sequence of [a] and laryngeals [2,h] or pharyngeals [ $\mathrm{i}, \mathrm{H}]$ : [maSlaHa] 'interest', [SaHHaahaa] 'he awakened her', [ [Tainnak] 'your stabbing'

- Blocked by following high segment: [SiHHa] 'health' and [Syaam] 'fast'

The local rightward harmony affects the next vowel nucleus, including any intervening consonant, and the long-distance harmony affects a sequence of low segments, a class that includes the vowel [a] and the laryngeal and pharyngeal gutturals. Both processes take place as long as no violations of RTR/Hi (*[high, RTR]) occur. RTR/Hi is highly ranked, and it is in agreement with RTR/Lower-VT 'If [RTR], then Lower vocal tract'. McCarthy assumes that [a] and the gutturals have a lower vocal tract node in the feature geometric representation. This constraint requires that any segment that is specified as [RTR] should have a lower vocal tract node; that is, it must be a pharyngeal sound (a low vowel or a guttural consonant). This constraint assigns a violation mark to every segment with an [RTR] feature that does not also have the lower vocal tract node. Another constraint that plays a key role in local and long-distance harmony is RTR-to-a, which requires any [RTR] span to end on the vowel [a]. This constraint is important to account for forms like [abaaH] and [?aDlam], and it is not problematic for long-distance harmony in forms like [SaHHaahaa] because in all these forms the harmony proceeds to the vowel [a] regardless of its medial or final position. McCarthy (1997, p. 244) argues that the interaction between the constraints above with other constraints like RTR-LEFT and RTR-RIGHT yields the following ranking for northern Palestinian Arabic:

(20) IDENT-RTR, RTR-LEFT >> RTR/Hi >> RTR-To-a >> RTR/Lower-VT >> RTR-RIGHT $>>$ IDENT-ATR

10 Regarding the fact that OT explains the phonology of any language by ranking of the set of universal constraints, OT seems more explanatory than FG. As a natural consequence of OT, a markedness constraint can be ranked higher than the constraint that motivates harmony in one direction but lower than the constraint that motivates harmony in another. Whereas FG approach may attempt to account for blocking segments in terms of their feature specifications, it is not clear how that can be explanatory for segments that block harmony in one direction but not the other. 
The top-ranked IDENT-RTR requires that the output must retain the [RTR] feature of the emphatic segment, that is, the emphatic segment cannot be de-emphasized. This constraint and RTR-LEFT ensure that leftward harmony is unimpeded by any segments. RTR/Hi is higher in ranking than other constraints since the presence of a high segment like [i] or [u] blocks the spread of [RTR] to

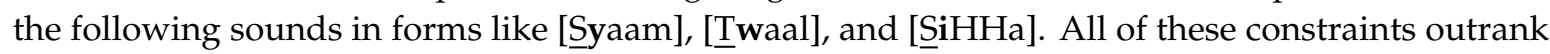
RTR-RIGHT in order to account for blocking effects in rightward harmony. The faithfulness constraint IDENT-ATR is the lowest in the ranking and is violated in every case of [RTR] harmony.

In support of the ranking above, McCarthy (1997, pp. 245-47) provides a number of tableaux. The first one shows a case of local harmony in which [RTR] spreads only to the next vowel as follows:

(21) Local harmony and the spread to [a] (McCarthy 1997, p. 245)

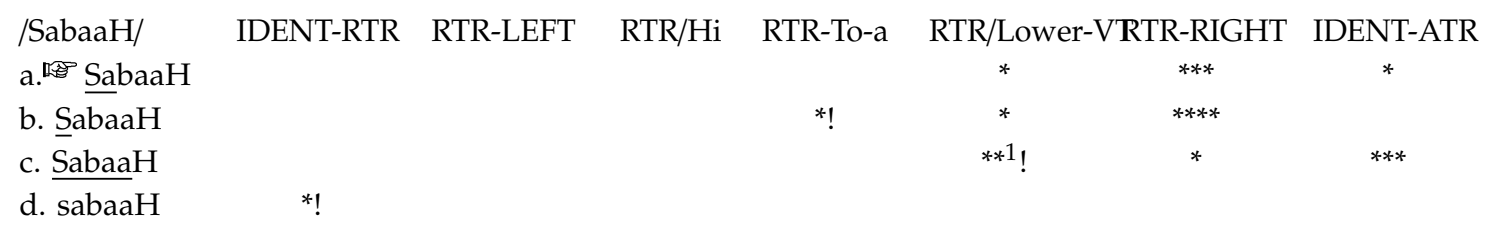

Candidate (b) incurs a fatal violation of RTR-To-a since the right edge of the [RTR] span is not the vowel /a/ (in candidate (a), although [RTR] does not span to end on the second vowel [a] in [SabaaH], this does not incur a violation to the RTR-To-a constraint because it is sensitive to the syllable boundary in which the emphatic sound occurs, in other words, since the second [a] exists in the second syllable in [Sa.baaH], the [RTR] feature is not supposed to span to it). Candidate (c), with long-distance harmony, violates RTR/Lower-VT twice because /S/ and /b/ have [RTR] without having the lower vocal tract node. Form (d) satisfies all [RTR]-controlling constraints by disregarding the feature, but that violates top-ranked IDENT-RTR.

Tableau (22) below demonstrates another case of local harmony with the consonant $/ \mathrm{n} /$ included within the [RTR] span. Candidate (b) loses the competition because it incurs a fatal violation to the high-ranking constraint RTR-To-a which requires any [RTR] span to end on the vowel [a].

(22) Local harmony and the inclusion of a nasal (McCarthy 1997, p. 245)

\begin{tabular}{|c|c|c|c|c|c|c|c|}
\hline $\begin{array}{l}\text { /Snaaf/ } \\
\text { a. 啗 Snaaf }\end{array}$ & IDENT-RTR & RTR-LEFT & $\mathrm{RTR} / \mathrm{Hi}$ & RTR-To-a & $\underset{* *}{\mathrm{RTR} / \text { Lower-VT }}$ & $\begin{array}{c}\text { RTR-RIGHT } \\
*\end{array}$ & $\underset{* *}{\text { IDENT-ATR }}$ \\
\hline b. Snaaf & & & & $* !$ & * & $* * *$ & \\
\hline
\end{tabular}

Tableau (23) shows a case of local harmony blocked by following high segment [s].

(23) The effect of the high segment [J] (McCarthy 1997, p. 246)

\begin{tabular}{|c|c|c|c|c|c|c|c|}
\hline 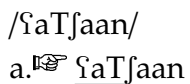 & IDENT-RTR & RTR-LEFT & $\mathrm{RTR} / \mathrm{Hi}$ & $\begin{array}{c}\text { RTR-To-a } \\
*\end{array}$ & $\begin{array}{c}\text { RTR/Lower-VT } \\
*\end{array}$ & $\underset{* * *}{\text { RTR-RIGHT }}$ & $\underset{* *}{\text { IDENT-ATR }}$ \\
\hline b. IaTJaan & & & $* !$ & & * & * & $* * * *$ \\
\hline c. IaTJaan & & $*$ ** & & * & * & $* * *$ & \\
\hline
\end{tabular}

The effect of blocking can be seen by comparing candidates (a) and (b). The former satisfies $\mathrm{RTR} / \mathrm{Hi}$ since the high consonant/S/ blocks the spread of [RTR]. Candidate (b) violates this high-ranking

1 The [pharyngeal] feature distinguishes sounds articulated in "the area from the larynx and oropharynx inclusive" (McCarthy 1994, p. 198). (Rose 1996) argues that the pharyngeal sounds are divided into two subgroups according to the shape of the tongue root: the first subgroup include non-laryngeals sounds (i.e., uvulars, pharyngeals and emphatics) that have the [RTR] feature because they are articulated by constricting the pharynx or retracting the tongue root, and the second subgroup includes only laryngeals that have [ATR] feature since they are produced with tongue root advancement, rather than retraction (for an overview, see (Vaux 1996)). 
constraint by allowing / $/ \mathrm{f}$ to assimilate to the [RTR] feature. Candidate (a) bests (b) since the former violates the lower-ranked RTR-To-a (i.e., harmony is blocked and does not proceed to/a/). The candidate (c) incurs fatal violations to the higher-ranked RTR-LEFT since leftward harmony does not affect the preceding segments $/ \mathrm{i} /$ and $/ \mathrm{a} /$.

To sum up, rightward and leftward emphasis harmony do not have the same behavior. The progressive spread is more restricted since it is blocked by high front segments. These observations may lead to the conclusion that leftward harmony is the default or the unmarked direction of emphasis harmony. The question here is why high front segments are the only sounds that block the process of harmony. The answer to this question may be related to language production. According to Hansson (2001, p. 446), harmony is related to phonological encoding for speech production. To illustrate, Hansson points out that

consonant harmony processes are driven—or at the very least facilitated-by the relative similarity of the interacting segments; the more similar two cooccurring consonants are, the more likely it is that they will be forced to agree with one another in some particular feature.

Therefore, the similarity between segments paves the way for spreading to take place. Regarding emphasis harmony, the articulation of pharyngealized coronals is entirely different from that of high front segments. According to Watson (2002, p. 276), the articulation of high front segments, which is characterized by pharyngeal expansion, is incompatible with the articulation of emphatics, which requires pharyngeal constriction. The basic differences of articulation between high front segments and emphatics may be the reason behind the blocking effect of the former. However, another question needs to be addressed: why high front segments cannot block leftward spreading. From a phonological perspective, at least in McCarthy's analysis, the constraint requiring leftward alignment of RTR is ranked above the constraint requiring rightward alignment with the markedness constraint against high segments with RTR being ranked between the two. Considering the phonetic factor, the answer to this question may lie in the domain of speech planning. In leftward harmony, the anticipation of the emphatic coronal affects the cavity of the pharynx and makes premature pharyngeal constriction which affects all the preceding sounds. In rightward harmony, the emphatic is already produced, and the articulation of the high front segment takes priority to be prepared and planned for, that is, a stop to the spread of [RTR] is inevitable to plan for the production of the approaching high front segment.

To sum up, unlike rightward direction, leftward harmony is unrestricted by high front segments (i.e., [i], [y], [j], and [j]), and in the case of the absence of blockers, both directions are affected by the same types of constraints, namely, alignment and correspondence constraints. The alignment constraints, represented by RTR-RIGHT and RTR-LEFT, force emphasis harmony to spread into the designated rightward and leftward direction. These constraints are higher in ranking than the correspondence constraint IDENT-ATR, which requires that an input segment that has the feature [ATR] must retain this feature in the output. The given ranking for both directions (i.e., RTR-RIGHT $>>$ IDENT-ATR and RTR-LEFT >> IDENT-ATR) indicates that the markedness alignment constraints dominate the faithfulness correspondence constraint in order to enable the spread of the [RTR] feature from the emphatic segment to the following or the preceding sounds. In addition to the general alignment constraints, more specific ones also exist, such as RTR-To-a, which requires any [RTR] span to end on the vowel [a] in limited environments, as explained above.

While in the absence of blockers, only these types of constraints are effective in the process under discussion, another type of constraints comes into play in rightward harmony when the high front segments are present. This type of constraints includes a set of grounded constraints which are imposed by the physical properties of the vocal tract; that is to say, the phonological features of a given segment must abide by the phonetic bases of speech. In accordance with grounded constraints, high front segments act as blockers to emphasis harmony because their articulation prevents them from being retracted due to the difficulty of raising the tongue body and simultaneously retracting the root, consequently, these sounds cannot have both the [HI] and [RTR] at the same time. The grounded 
constraints proposed in the given studies above include three constraints, namely, RTR/Hi, RTR/HI\&FR, and RTR/Lower-VT. The first two prohibit the specification of [RTR] on high segments and high front vowels, respectively, and the third constraint RTR/Lower-VT demands that any segment with [RTR] should be specified with a lower vocal tract node. However, the theoretical consequences that can be argued based on the interplay of the mentioned constraints are in support of optimality theory as an adequate approach to account for emphasis harmony, that is, the interaction between the three types of alignment, correspondence, and grounded constraints does not only provide the optimal outputs in Arabic dialects but also account for other phonological processes that accompany emphasis harmony, such as labialization, which is explained in the next subsection.

\subsection{Labialization}

Although pharyngealization is the most prominent aspect of emphatic harmony in all Arabic dialects, it is not the only articulatory feature involved. In addition to pharyngeal constriction, "lip-protrusion or lip-rounding is the most obvious and certainly the most visually salient enhancing feature of the emphatic phonemes". Lip-rounding or labialization is combined with pharyngealization to create the auditory impression of 'darkening' (Watson 2002, p. 269) ${ }^{12}$. This aspect can be found in a number of Arabic dialects in which emphatic segments cause the neighboring vowel to be rounded. In this section, the different characteristics of this phonological process are illustrated in three Arabic varieties, namely, Baghdadi, Syrian, and Jordanian Arabic. In Baghdadi Arabic, labialization seems the most complicated process which is influenced not only by emphatics but also by labial segments. Youssef (2015) points out that the epenthetic high front vowel /i/ appears as [u] in the environment of either one labial-velar glide or by the collective influence of neighboring labial and emphatic/velar/uvular consonants. The second environment involves the presence of back consonants (i.e., velars and uvulars in addition to emphatics, which are further distinguished from other back consonants for their primary and secondary articulation). The effect of back consonants along with labials causes the underlying /i/ to surface as [u] since they spread both [labial] and [dorsal] features to the underlying vowel. Youssef (2015) exemplifies this process as it occurs in epenthetic vowels in derived nouns and stem vowels in verbs. Regarding derived nouns, the epenthetic vowel in a final consonant cluster appears as $[u]$ in specific consonantal environments as follows: "If the cluster consists of a labial [p, b, f, m] followed or preceded by a velar [g, $x, y]$, uvular [q], liquid [r], or emphatic [T, S, D, Z] (collectively, back consonants), the E[penthetic] V[owel] is always [u] as exemplified in [24a,b] (Blanc 1964, p. 56; cited in Youssef 2015, p. 75). The same pattern is observed when the cluster consists of a labial and some other consonant provided the initial consonant is an emphatic [24c]".

(24) Labial and back consonants as joint triggers of epenthetic [u] a. [nafux] 'inflating', [dabuy] 'tanning', [waquf] 'religious endowment', [Harub] 'war'

b. [iaTuf] 'compassion', [habuT] 'dropping', [TamuS] 'bogging down'

c. [Tabu§] 'printing', [Tabul] 'drumming', [Tafum] 'taste', [Safun] 'meditating'

In (24a), the forms [nafux] and [dabuy] involve two joint triggers of labialization, namely, the labial $[f, b]$ and the velar $[x, y]$. The form [waquf] exemplifies the effect of the uvular [q] and the labial [f]. [Harub] involves a liquid [r] and a labial [b]. In (24b), the forms [YaTuf], [habuT] and [TamuS] involve an emphatic [T, S] and a labial [f, b, m]. The forms in (24c) include an initial emphatic and a labial before the epenthetic vowel. These cases are summarized in (25):

(25) Summary of labialization in $\mathrm{CaCvC}$ nouns (Youssef 2015, p. 76)

12 As highlighted by the reviewer, unlike pharyngealization which is a salient feature of all emphatic sounds, labialization is a feature that is involved in the production of some emphatics (i.e., [T] and [S]), but not others (i.e., [D] and [Z]). 


$\begin{array}{llll}\mathrm{C}_{1} & \mathrm{C}_{2} & \mathrm{~V} & \mathrm{C}_{3} \\ \text { Any } & \text { Labial } & {[\mathrm{u}]} & \text { Back: emphatic or } \\ \text { Any } & \text { Back: emphatic or non-emphatic } & {[\mathrm{u}]} & \text { non-emphatic } \\ \text { Back: emphatic } & \text { Labial } & {[\mathrm{u}]} & \text { Any } \\ \text { Back: emphatic } & \text { Any } & {[\mathrm{u}]} & \text { Labial }\end{array}$

The first two domains show that the labial and the back consonant can occur in either order when they are adjacent to the vowel. The last two domains demonstrate that when the initial consonant is an emphatic segment, the labial can occur either before or after the vowel. However, apart from these domains, the epenthetic vowel is always [i]. In addition to the epenthetic vowels in derived nouns, the stem vowels in verbs appear as [u] instead of [i] in the same environments discussed above, as can be seen in examples like [fuqad] 'he lost', [Tufar] 'he jumped', and [laufaD] 'he enunciated'. Apart from these domains, [i] occurs ${ }^{13}$.

To sum up, the labialization of [i] is determined by the existence of labial and back consonants. This requirement indicates the effect of specific features on the vowel. The spread of such features is analyzed by Youssef (2015) from two theoretical perspectives, namely, autosegmental (feature-geometric) and optimality-theoretic accounts.

Regarding the autosegmental representation, Youssef (2015) adopts the parallel structure model proposed by Morén (2003) which considers consonants and vowels to exhibit parallel structures and identical features for place, manner, and laryngeal articulations as below (Figure 7):

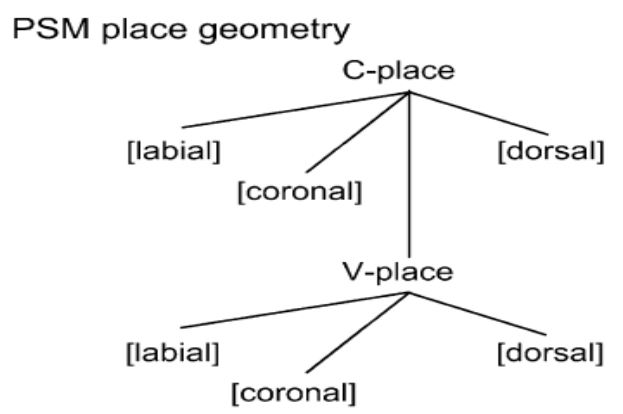

Figure 7. The parallel structure model (Youssef 2015, p. 80).

According to Youssef (2015, pp. 80-81), in Baghdadi Arabic the consonants $[\mathrm{p}, \mathrm{b}, \mathrm{f}, \mathrm{m}]$ are characterized by a C-place [lab] feature. The class of emphatics is specified for C-place [cor] and V-place[dor]. The class of velars and the uvular have the C-place [dor]. Because the liquid [r] has the back articulation, it is characterized not only with C-place [cor] but also with C-place [dor]. Following Clements and Hume (1995), [i] has the V-place [dor] feature, and [u] is specified for V-place [lab] and V-place [dor]. Bearing in mind the previous features of the given segments, spreading from a labial and an emphatic involves the spread of the feature [labial] locally from an adjacent labial consonant and the spread of [dor] feature from an emphatic, as represented below (Figure 8) (Youssef 2015, p. 82):

13 Watson (2002, p. 269) indicates that labialization of the stem vowel in verbs occurs in other Arabic dialects when one of the root consonants is an oral emphatic. In Lebanese, for example,/rixiS/ 'it became cheap' becomes [ruxis], and in the Yemeni dialect of Baraddun /yigiSS/ 'he cuts' surfaces as [yiguSS]. 


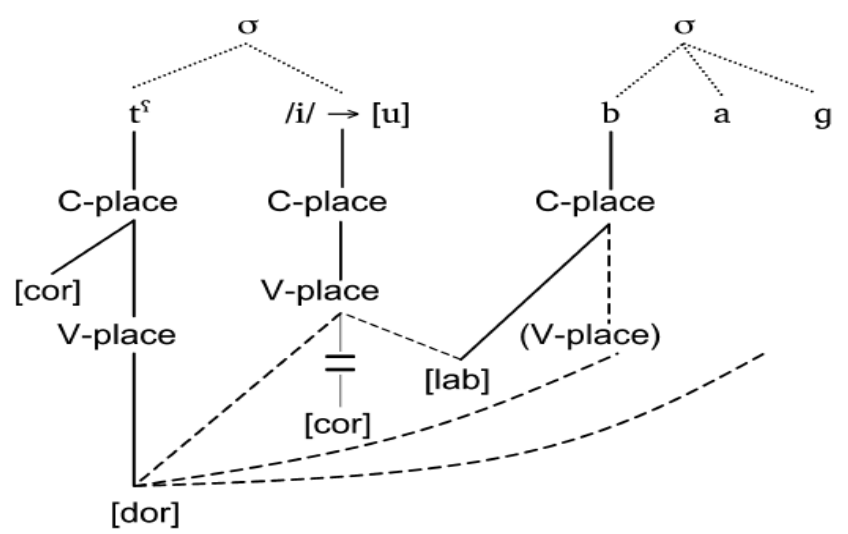

Figure 8. The change from /Tibag/ to [Tubag] (Youssef 2015, p. 82).

In this diagram, two simultaneous spreading operations take place. The emphatic/T/ spreads the [dor] feature to /i/ (and to other segments as well), and the labial/b/spreads [lab] feature. The result of these two operations is that $/ \mathrm{i} /$ surfaces as [u] with [lab] and [dor] features.

From a constraint-based perspective, labialization is the result of the interaction of several markedness and faithfulness constraints. Firstly, in order to account for epenthesis, a markedness constraint against coda clusters, ${ }^{*} \mathrm{C}_{\mathrm{OMP}} \mathrm{C}_{\mathrm{ODA}}$, must outrank a faithfulness constraint against vowel insertion, $\mathrm{D}_{\mathrm{EP}} \mathrm{V}$-[cor] (i.e., do not insert [i]). Depending on the previous autosegmental representations above, labialization is the result of the spread of both [lab] and [cor] features. For the epenthetic vowel, two alignment constraints are needed to link the given features as below:

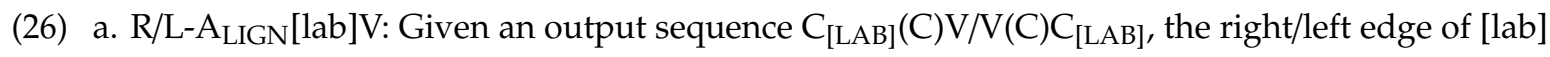
must be aligned to the right/left edge of the sequence.

b. R/L-A $A_{\text {LIGN }}\left[\right.$ dor]V: Given an output sequence $C_{[D O R]}(C) V / V(C) C_{[D O R]}$, the right/left edge of [dor] must be aligned to the right/left edge of the sequence.

Regarding the stem vowel in verbs, Youssef (2015, p. 84) argues that "spreading V-place[dor] is independently motivated via bidirectional emphasis spread in the stem word domain" because unlike labials and non-emphatic back consonants, emphatics need not be adjacent to the target vowel. Thus, the following alignment constraint is needed:

(27) Align V-[dor] $]_{\text {STEM }}$ : The right/left edge of V-place[dor] must be aligned to the right/left edge of the stem word.

However, these alignment constraints work against $\mathrm{D}_{\mathrm{EP}} \mathrm{L}_{\mathrm{INK}}$ faithfulness constraints which prevent linking some feature to a segment that did not have it underlyingly. Thus, for spreading to take place, the alignment constraints must outrank the following $\mathrm{D}_{\mathrm{EP}} \mathrm{L}_{\mathrm{INK}}$ faithfulness constraints:

(28) a. $\mathrm{D}_{\mathrm{EP}} \mathrm{L}_{\mathrm{INK}}$ [lab]: An output association between a [lab] feature and a root node must have a corresponding association in the input.

b. $D_{\mathrm{EP}} \mathrm{L}_{\mathrm{INK}}$ [dor]: An output association between a [dor] feature and a root node must have a corresponding association in the input.

The effect of these constraints can be seen in a form like [Tabui] in which the emphatic/T/ and the labial $/ \mathrm{b} /$ are the triggers of labialization of $/ \mathrm{i} /$, that is, the change from $/ \mathrm{Tabi} \mathrm{i} /$ to [Tabu $\mathrm{C}$ ]. The following tableau is illustrative (Youssef 2015, p. 85):

(29) the change from/Tabis/ to [Tabui]

\begin{tabular}{|c|c|c|c|c|c|c|}
\hline /Tabi/ & ${ }^{*} \mathrm{C}_{\mathrm{OMP}} \mathrm{C}_{\mathrm{ODA}}$ & $\begin{array}{l}\text { R/L-A } A_{\text {LIGN }} \\
{[\mathrm{lab}] \mathrm{V}}\end{array}$ & $\begin{array}{l}\text { Align } \\
\text { V-[dor] }\end{array}$ & $\mathrm{D}_{\mathrm{EP}} \mathrm{V}$-[cor] & $\begin{array}{l}\mathrm{D}_{\mathrm{EP}} \mathrm{L}_{\mathrm{INK}} \\
\text { [dor] }\end{array}$ & $\begin{array}{l}\mathrm{D}_{\mathrm{EP}} \mathrm{L}_{\mathrm{INK}} \\
{[\mathrm{lab}]}\end{array}$ \\
\hline a. Tabs & ${ }^{*} !$ & & $*$ & & & \\
\hline b. Tabi؟ & & $* !$ & $*$ & * & & \\
\hline Tabu & & & & & $* * * *$ & $*$ \\
\hline
\end{tabular}


In order to get the right optimal output, the ranking ${ }^{*} \mathrm{C}_{\mathrm{OMP}} \mathrm{C}_{\mathrm{ODA}}, \mathrm{R} / \mathrm{L}-\mathrm{A}_{\mathrm{LIGN}}[\mathrm{lab}] \mathrm{V}$, Align $\mathrm{V}$-[dor] $]_{\text {STEM }}>>\mathrm{D}_{\mathrm{EP}} \mathrm{V}$-[cor], $\mathrm{D}_{\mathrm{EP}} \mathrm{L}_{\mathrm{INK}}$ [dor], $\mathrm{D}_{\mathrm{EP}} \mathrm{L}_{\mathrm{INK}}$ [lab] must hold. Based on this ranking, the faithful candidate (a) [TabS] without epenthesis is rejected because it has a complex coda. Candidate (b) [Tabi 1 ] with an epenthetic [i] loses the competition because it violates the high-ranking alignment constraints

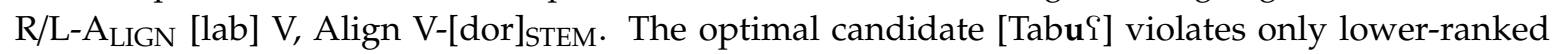
faithfulness constraints and wins the competition. To conclude, both autosegmental and optimality theoretic accounts show the effect of an emphatic consonant on the vowel to be labialized. In Baghdadi Arabic, the emphatic segment cannot by itself change the vowel to be rounded since, as discussed before, this process requires the joint spread of two features at the same time. This gang-up effect is not necessary for other Arabic dialects, as the next paragraphs show.

Oyoun Al-Wadi, a Syrian rural variety, exhibits another instance of labialization caused by emphatic consonants. According to Habib (2012, p. 60), "whenever emphasis occurs in a word, it induces rounding in the final syllable". That is, emphatics make final vowels raise to mid-position and be rounded, as in /xalaS/ [xaloS] 'enough/it is finished' and /ytвa:laZ/ [ytва:loZ] 'he acts thick'. The spread of [RTR] in leftward harmony seems effective only on the neighboring vowel, and adjacency is a requirement for the emphatic to labialize the vowel. This requirement does not hold in rightward harmony which can affect the final vowel even if it is not adjacent to it, as in /Sayya:d/ [Sayyo:d] 'hunter' and /PitSaffan/ [?itSaffon] 'I contemplate'. However, the limitation of both types of harmony is restricted not only to one vowel but also to the place of the syllable; that is, emphatic harmony causes the change of /a/ to [o] only if the vowel is in the final syllable. ${ }^{14}$

To sum up, labialization in Oyoun Al-Wadi is caused by emphatics only, and there is no effect of other segments like labials (as in Baghdadi Arabic). It is also seen that labialization is restricted to the final position according to the markedness constraint ${ }^{*} \mathrm{Ca} / \mathrm{a}: \mathrm{C \#}$, and it is also restricted to the vowel [a] (compared to [i] in Baghdadi Arabic). Like in Baghdadi and Syrian Arabic, labialization takes place in San'ani, a Yemeni dialect. Lip-rounding affects front vowels like/i/ which is realized as $[\mathrm{u}]$ in the

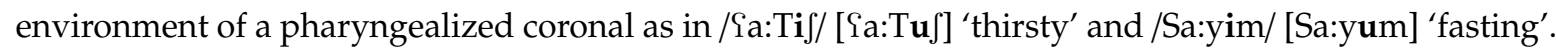
Labialization has a larger domain; it also affects suffixes like in /yiwaSSul-ih/ [yiwaSSul-uh] 'he brings it' and /faSl-i $\mathbf{j} /[$ faSl-u]] 'your f.s. class'.

Watson (2002, p. 282) points out that unlike pharyngealization, labialization in San'ani (and also in Baghdadi and Syrian Arabic) is not blocked by high front vowels to the right of the emphatic. In Watson's (2002) analysis, labialization is considered as a spread of the [lab] feature from the emphatic segment as in the form /magTubih/ which surfaces as [magTubuh] 'diligent'. The spread of the [lab] feature from $/ \mathrm{T} /$ causes the high front vowel /i/ to become $[\mathrm{u}]$. This indicates that $/ \mathrm{i} /$ which blocks rightward spread of [RTR] is transparent to [lab] spread. In other words, /i/ is considered as a strong segment in the process of [RTR] spread, but it is weak in labialization since it cannot resist assimilation to $[u]$.

In contrast to rightward labialization, the leftward spread of [lab] is more restricted, that is, the /i/ vowel is realized as [u] only if it occupies the position immediately to the left of the emphatic as in /alaxbiT/ [alaxbuT] 'I get mixed up'. Based on these observations, Watson $(2002$, p. 284) indicates the two phonological exponents involved in emphatic harmony - pharyngealization and labialization-are different from each other regarding their direction. While rightward spread of [RTR] is the unmarked direction of pharyngealization, leftward is the unmarked direction of [lab] spread.

In Jordanian Arabic, Alghazo (2013, p. 349) points out that labialization targets elements beyond the word boundary, as can be seen in a verb like/yi-Drub/ which surfaces as [yu-Drub] 'he hit'. In this example, the high front vowel/i/ does not block [RTR] spread, instead, it is affected by the process and becomes $[u]$ as a result of obtaining [RTR] feature from $/ \mathrm{D} /$.

14 As pointed out by the reviewer, this phenomenon cannot be generalised to all Syrian dialects, and most probably to be restricted only to Oyoun Al-Wadi. 
To sum up, labialization is considered as an enhancing feature that goes hand in hand with pharyngealization. The spread of [lab] feature is not identical in the aforementioned Arabic varieties, as can be seen in their differences regarding the triggers, the domain, and direction of labialization. In Baghdadi Arabic, the existence of an emphatic segment is not enough for the process to take place, and the need for a labial is essential for the process to take place, and this joint effect of a labial and an emphatic is not required in Syrian, Yemeni, and Jordanian Arabic. Concerning the domain of labialization, Baghdadi and Syrian Arabic represent more restricted domains of rounding since labialization does not affect suffixes and enclitics like in San'ani and Jordanian Arabic. The different directions of [lab] spread is not considered in Baghdadi and Syrian Arabic, and the view that leftward is the unmarked direction of [lab] spread needs more research in order to be verified in other Arabic varieties.

\subsection{Spread from Secondary Emphatic/ $r \mid$}

The discussion of emphasis spread in previous sections deals with the emphatic coronals $/ S, Z, D$, and T/ which are considered as the primary emphatics. According to Watson (2002) and Habib (2012), emphasis may also spread from the liquid / $\mathrm{r} /$. In San'ani Arabic, $/ \mathrm{r} /$ triggers emphasis in both leftward and rightward directions, and the spread is blocked by high front segments like /i/ as exemplified in $(30 \mathrm{a}, \mathrm{b})$ :

(30) a. Leftward harmony: [infiga:r] 'explosion' [sifa:ra] 'embassey'

b. Rightward harmony: [ruma:di] 'grey' [ra:gil] 'man'

The spread of [RTR] from / $r$ s seems similar to that from other pharyngealized coronals, in the sense that it affects all segments except high front vowels which put a stop to the spread. In these examples, $/ \mathrm{r} /$ has the same effect as emphatic coronals. However, what makes / $\mathrm{r} /$ different from coronals is that it gets de-emphasized when it comes in direct contact with high front segments, as in the following examples (Watson 2002, p. 276):

(31) a. [saar] 'he went', [xaddar] 'he stupefied', [akbar] 'older'

b. [saayir] 'going', [taxdiir] 'stupefying', [kabiir] 'old'

In (31a) the given forms exemplify the case in which $/ \mathrm{r} /$ spreads emphasis leftward and targets all preceding segments. In these examples, $/ \mathrm{r} /$ is an emphasized sound, and it targets preceding segments. In (31b), the forms show how $/ \mathrm{r} /$ gets de-emphasized when it comes in direct contact with the blocker /i/. De-emphasis of /r/ also takes place when the blocker follows / $/ \mathrm{r}$ as in (32b):

(32) a. [tigaara] 'trade', [?idaara] 'administration', [fa?r] 'poverty'

b. [tigaari] 'trade adj.', [?idaari] 'administrative', [fa?ri] 'poor adj. ${ }^{15}$

Habib (2012, p. 60) argues that in Oyoun Al-Wadi, a rural Syrian variety, [r] causes emphatic harmony and rounding bidirectionally. In the following examples, leftward harmony is triggered by $[r]$ to the preceding segments in (33a), and rightward harmony affects the following segments in (33b):

(33) a. [?asfor] 'yellow', [' aqurob] 'scorpion', [?itzakkor] 'I remember'

b. [ro:H] 'he went', [Diro:r] 'proper name', [ma:rimo:r] 'proper name'

Habib raises an important question about the common feature between emphatics and $[r]$ that makes these sounds trigger rounding of the vowel, although $[\mathrm{r}]$ is not a pharyngealized consonant like emphatics. The answer to this question, as argued by Habib (2012, pp. 61-62), lies in the phonetic articulation of these sounds. [r] has a secondary pharyngeal feature since it is produced with an aryepiglottic constriction. The articulation of $[\mathrm{r}]$ makes it similar to emphatic obstruents in exhibiting

15 (Watson 2002, p. 275) mentions the form [dira:sa] 'learning' in which [r] is emphasised although it is adjacent to [i]. It is not clear whether this is a typo or not, therefore, the deemphasis of $/ \mathrm{r} /$ needs further research to be verified. 
low frequency of the second formant (F2), an acoustic feature of emphasis. Emphatics and [r] cause lowering of F2 in adjacent vowels because of the pharyngeal constriction or the retraction of the dorsum. Based on these facts, Habib (2012, p. 62) indicates that "since the lowering of F2 is associated with backness and constriction of the tongue, it is not surprising that the variety of Oyoun Al-Wadi shows rounding of the vowels [a] and [a:] in the environment of emphatics". In support of this view, Watson (2002, p. 270) indicates that

since labialization has the acoustic effect of lowering F1, while pharyngealization has the effect of raising F1, the fact that labialization is an enhancing feature, particularly in the oral emphatics, is further evidence that F2 lowering is more significant than F1 raising in the identification of emphasis.

\section{Summary and Conclusions}

This paper provides a comprehensive view of emphasis harmony in Arabic dialects from FG and OT perspectives. From the FG account, McCarthy (1994) argues that emphatic segments belong to the guttural group since they share several phonetic properties and phonological patterns found in other pharyngeal, uvular, and laryngeal consonants. Therefore, he concludes that the salient phonological feature in all Semitic gutturals is [pharyngeal]. Rose (1996) argues for the replacement of this feature with [RTR] to distinguish between laryngeals and non-laryngeals. However, McCarthy (1994) and Rose (1996)'s views have been questioned and challenged recently by some researchers like Al-Solami (2017) and Altairi et al. (2017), who argue for the exclusion of emphatics from the guttural group. The given arguments lead to a number of observations regarding the adequacy of FG approach. These observations can be presented as points of strengths and weaknesses of this approach. The main strength is that all researchers agree that the process of emphasis harmony is an autosegmental spreading of a phonological feature from a guttural sound to adjacent vowels and consonants. The second point is that recent studies adopting OT still utilize the notion of feature spreading as used in FG to propose some markedness constraints to account for emphasis harmony, as well as other phonological processes such as labialization. Apart from these points, the FG approach suffers several weaknesses that can be argued as follows: First, researchers cannot reach a consensus regarding which consonants belong to the guttural group, and which features are shared between these consonants. The conclusion of the discussed proposals is that FG may be inadequate to provide an accurate description of gutturals simply because one phonological feature cannot be shared between all gutturals in all languages (and most probably, not even all varieties of the same language (e.g., Arabic)).

Second, there is wide disagreement among researchers regarding the consonants that trigger emphasis harmony in Arabic. In some studies (e.g., McCarthy 1994), dorso-pharyngeal sounds trigger emphasis harmony, while in others (e.g., Rose 1996) emphatics, uvulars, and pharyngeals cause emphasis harmony. The third weak point is related to directional spreading and blocking. FG fails to explain in which direction the spread takes place and which segments block harmony and why. This demerit is caused by the essence of FG that focuses on the grouping of sounds by virtue of the presence/ absence of a particular feature, that is, FG may attempt to account for blocking segments in terms of their feature specifications, but it is unable to demonstrate clearly how that can be explanatory for segments that block harmony in one direction but not the other. Fourth, FG wrongly predicts that the process of spreading is an absolute phenomenon in the sense that it has the same effect in all varieties of Arabic language.

From an OT perspective, researchers are more concerned with the constraints that affect phonological processes than with arguments for grouping of segments. This attitude provides a more comprehensive view of emphasis harmony. In this paper, the different OT analyses are viewed to describe the essential aspects of emphasis harmony, namely, directional spreading and blocking, spread from secondary emphatic/r/, and labialization. Concerning the first aspect, the direction of spreading can be leftward or rightward, the leftward direction is shown to be the default, unmarked pattern since it cannot be blocked by high front segments. Regarding the second aspect, the spread of 
[RTR] from $/ r$ s seems similar to that from other pharyngealized coronals in the sense that it affects all segments except high front vowels, but/r/ gets de-emphasized when it comes in direct contact with blockers. Finally, labialization is considered to be an enhancing feature that provides more darkening effects for emphasis. The labialization process is shown to be different from one dialect to another depending on the segments involved in the process.

However, this paper reaches two main conclusions. Firstly, OT can provide a more comprehensive view and a clearer picture of emphasis harmony than FG. As can be seen in the discussion above, OT explains the phonological aspects of emphasis (e.g., directional spreading and blocking, involvement of emphatic/r/, and labialization) in an accurate and detailed way which does not only clarify the process in one Arabic dialect but also describes the differences between dialects due to the merit of (re)ranking of constraints. Moreover, the same aspect, for example, directional spreading, cannot be explained fully by FG which depends on accounting for blocking effects of some segments in terms of their feature specifications, and that does not provide why such segments can be blockers in one direction but not the other. The second conclusion is that emphasis harmony is different from one Arabic dialect to another regarding its direction, involvement of emphatic/r/, and labialization. These differences between dialects indicate that emphasis harmony is not an absolute phenomenon.

Funding: This research received no external funding.

Acknowledgments: In various stages of the paper's development, I benefited greatly from discussions with Sara Mackenzie whose insightful comments and constructive feedback helped me improve the quality of the paper. I would like also to thank three anonymous reviewers for valuable comments and suggestions.

Conflicts of Interest: The author declares no conflict of interest.

\section{Abbreviations}

Transcriptions of Arabic guttural sounds.

$\begin{array}{ll}\text { Symbol } & \text { Description } \\ \mathrm{H} & \text { Voiceless pharyngeal fricative } \\ \mathrm{X} & \text { Voiceless velar fricative } \\ \mathrm{T} & \text { Voiceless dento-alveolar emphatic stop } \\ \mathrm{D} & \text { Voiced inter-dental emphatic fricative } \\ \mathrm{S} & \text { Voiceless dento-alveolar emphatic fricative } \\ \mathrm{Z} & \text { Voiced dento-alveolar emphatic stop } \\ \mathrm{I} & \text { Voiced pharyngeal fricative } \\ \mathrm{B} & \text { Voiced velar fricative } \\ \mathrm{q} & \text { Voiceless uvular stop }\end{array}$

\section{References}

Al-Ani, Salman H. 1970. Arabic Phonology: An Acoustical and Physiological Investigation. The Hague: Walter de Gruyter.

Alghazo, Mohammad. 2013. Tongue Root Harmony in North Jordanian Arabic: An Optimal Domains Theory (ODT) Analysis. European Journal of Social Sciences 38: 344-51.

Algryani, D. Ali. 2014. Emphasis Spread in Libyan Arabic. International Journal on Studies in English Language and Literature 2: 30-38.

Al-Masri, Mohammad, and Allard Jongman. 2004. Acoustic correlates of emphasis in Jordanian Arabic: Preliminary results. In Proceedings of the 2003 Texas Linguistics Society Conference. Somerville: Cascadilla Proceedings Project, pp. 96-106.

Al-Solami, Majed. 2013. Arabic Emphatics: Phonetic and Phonological Remarks. Open Journal of Modern Linguistics 3: 314-18. [CrossRef]

Al-Solami, Majed Abdullah. 2017. Ultrasound Study of Emphatics, Uvulars, Pharyngeals and Laryngeals in Three Arabic Dialects. Canadian Acoustics 45: 25-35. 
Altairi, Hamed, Jason Brown, Catherine Watson, and Bryan Gick. 2017. Tongue Retraction in Arabic: An Ultrasound Study. Proceedings of the Annual Meetings on Phonology 4. [CrossRef]

Archangeli, Diana B., and Douglas George Pulleyblank. 1994. Grounded Phonology. Cambridge: MIT Press.

Archangeli, Diana, and Douglas Pulleyblank. 1998. Grounded Phonology (Current Studies in Linguistics 25). Cambridge: MIT Press, vol. 34.

Avery, Peter, and Keren Rice. 1989. Segment structure and coronal underspecification. Phonology 6: 179-200. [CrossRef]

Bin-Muqbil, Musaed S. 2006. Phonetic and Phonological Aspects of Arabic Emphatics and Gutturals. Ph.D. dissertation, The University of Wisconsin-Madison, Madison, WI, USA.

Blanc, Haim. 1964. Communal Dialects in Baghdad. Cambridge: Harvard University Press.

Catford, John Cunnison. 1977. Fundamental Problems in Phonetics. Bloomington: Indiana University Press.

Chomsky, Noam, and Morris Halle. 1968. The Sound Pattern of English. Cambridge: The MIT Press.

Clements, George N. 1985. The Geometry of Phonological Features. Phonology Yearbook 2: 225-52. [CrossRef]

Clements, George N. 1990. The role of the sonority cycle in core syllabification. Papers in Laboratory Phonology 1 : 283-333.

Clements, George, and Elizabeth Hume. 1995. The internal organization of speech sounds. In The handbook of phonological theory. Edited by John A. Goldsmith. Cambridge: Blackwell Publishers, pp. 245-306.

Davis, Stuart. 1995. Emphasis Spread in Arabic and Grounded Phonology. Linguistic Inquiry 26: 465-98.

Ghazeli, Salem. 1977. Back Consonants and Backing Coarticulation in Arabic. Ph.D. dissertation, The University of Texas at Austin, Austin, TX, USA.

Greenberg, Joseph H. 1950. The Patterning of Root Morphemes in Semitic. WORD 6: 162-81. [CrossRef]

Habib, Rania. 2012. Imala and rounding in a rural Syrian variety: Morphophonological and lexical conditioning. The Canadian Journal of Linguistics/La Revue Canadienne de Linguistique 57: 51-75. [CrossRef]

Halle, Morris, Bert Vaux, and Andrew Wolfe. 2000. On Feature Spreading and the Representation of Place of Articulation. Linguistic Inquiry 31: 387-444. [CrossRef]

Hansson, Gunnar. 2001. Theoretical and Typological Issues in Consonant Harmony. Ph.D. dissertation, University of California, Berkeley, CA, USA.

Herzallah, Rukayyah S. 1990. Aspects of Palestinian Arabic Phonology: A Non-Linear Approach. Ph.D. dissertation, Cornell University, Ithaca, NY, USA.

Jakobson, Roman, C. Gunnar Fant, and Morris Halle. 1951. Preliminaries to Speech Analysis: The Distinctive Features and Their Correlates. Cambridge: MIT Press.

Khedidja, Slimani, and Jisheng Zhang. 2017. Assimilation in the Djelfa Dialect of Algerian Arabic: An OT Account. Linguistics and Literature Studies 5: 213-23. [CrossRef]

Laufer, Asher, and Thomas Baer. 1988. The Emphatic and Pharyngeal Sounds in Hebrew and in Arabic. Language E Speech 31: 181-205.

Mahadin, Radwan S., and Yousef Bader. 1995. Emphasis assimilation spread in Arabic and feature geometry of emphatic consonants. Journal of Semitics 7: 87-113.

McCarthy, John. 1994. The phonetics and phonology of Semitic pharyngeals. Phonological Structure and Phonetic Form: Papers in Laboratory Phonology 3: 191-233.

McCarthy, John J. 1997. Process-Specific Constraints in Optimality Theory. Linguistic Inquiry 28: 231-51.

McCarthy, John J., and Alan Prince. 1995. Faithfulness and Reduplicative Identity. In Papers in Optimality Theory. Edited by Jill Beckman, Walsh Dickey and Suzanne Urbanczyk. Amherst: GLSA (Graduate Linguistic Student Association), Dept. of Linguistics, University of Massachusetts, pp. 250-384.

McFarland, Teresa Ann. 2009. The Phonology and Morphology of Filomeno Mata Totonac. Ph.D. dissertation, University of California, Berkeley, CA, USA.

Mielke, Jeff, and Elizabeth Hume. 2006. Distinctive Features. In Encyclopedia of Language E Linguistics, 2nd ed. Edited by Keith Brown. Amsterdam: Elsevier, pp. 723-31.

Moisik, Scott R., Ewa Czaykowska-Higgins, and John H. Esling. 2012. The epilaryngeal articulator: A new conceptual tool for understanding lingual-laryngeal contrasts. In Proceedings from Phonology in the 21st Century: In Honour of Glyne Piggott. Montreal: McGill University, vol. 22, pp. 1-15.

Morén, Bruce. 2003. The Parallel Structures Model of Feature Geometry. Working Papers of the Cornell Phonetics Laboratory 15: 194-270. 
Mustafawi, Eiman M. 2006. An Optimality Theoretic Approach to Variable Consonantal Alternations in Qatari Arabic. Ph.D. dissertation, University of Ottawa, Ottawa, ON, Canada.

Rose, Sharon. 1996. Variable Laryngeals and Vowel Lowering. Phonology 13: 73-117. [CrossRef]

Rose, Sharon, and Rachel Walker. 2011. Harmony Systems. In The Handbook of Phonological Theory. Edited by John A. Goldsmith, Jason Riggle and Alan C. L. Yu. Hoboken: John Wiley \& Sons, pp. 240-90.

Sagey, Elizabeth. 1990. The Representation of Features in Non-Linear Phonology: The Articulator Node Hierarchy. New York: Garland.

Shahin, Kimary N. 2003. Postvelar Harmony. Amsterdam: John Benjamins Publishing.

Shosted, Ryan K., Maojing Fu, and Zainab Hermes. 2017. Arabic pharyngeal and emphatic consonants. In The Routledge Handbook of Arabic Linguistics. Abingdon: Routledge, pp. 48-61.

Sylak-Glassman, John C. 2014. Deriving Natural Classes: The Phonology and Typology of Post-Velar Consonants. Ph.D. dissertation, University of California, Berkeley, CA, USA.

Vaux, Bert. 1996. The Status of ATR in Feature Geometry. Linguistic Inquiry 27: 175-82.

Watson, Janet. 2002. The Phonology and Morphology of Arabic. Oxford and New York: Oxford University Press.

Youssef, Islam. 2015. Vocalic labialization in Baghdadi Arabic: Representation and computation. Lingua 160: 74-90. [CrossRef]

(C) 2019 by the author. Licensee MDPI, Basel, Switzerland. This article is an open access article distributed under the terms and conditions of the Creative Commons Attribution (CC BY) license (http://creativecommons.org/licenses/by/4.0/). 